\title{
Evaluating the Cerebrospinal Fluid Tap Test With the Hellström iNPH Scale for Patients With Idiopathic Normal Pressure Hydrocephalus - a Retrospective Cohort Study of 132 Patients
}

Johanna Rydja ( $\sim$ johanna.rydja@regionostergotland.se)

Linköping University: Linkopings universitet https://orcid.org/0000-0002-2525-3309

Andreas Eleftheriou

Linköping University: Linkopings universitet

Fredrik Lundin

Linköping University: Linkopings universitet

Research

Keywords: Idiopathic normal pressure hydrocephalus, CSF TT, outcome, accuracy

Posted Date: December 7th, 2020

DOl: https://doi.org/10.21203/rs.3.rs-120167/v1

License: (c) (1) This work is licensed under a Creative Commons Attribution 4.0 International License.

Read Full License

Version of Record: A version of this preprint was published at Fluids and Barriers of the CNS on April 7th, 2021. See the published version at https://doi.org/10.1186/s12987-021-00252-5. 
1 Evaluating the cerebrospinal fluid tap test with the Hellström iNPH

2 scale for patients with idiopathic normal pressure hydrocephalus - a

3 retrospective cohort study of 132 patients

4

5 Authors' names

6 Johanna Rydja ${ }^{1 *}$, Andreas Eleftheriou ${ }^{2}$, Fredrik Lundin ${ }^{2}$

7 Affiliations

$8{ }^{1}$ Department of Activity and Health, and Department of Biomedical and Clinical Sciences,

9 Linköping University, Linköping, Sweden.

$10{ }^{2}$ Department of Neurology, and Department of Biomedical and Clinical Sciences, Linköping 11 University, Linköping, Sweden.

12

$13 *$ Corresponding author: Johanna Rydja, Department of Activity and Health, Linköping

14 University Hospital, SE581 85 Linköping, Sweden. Johanna.rydja@ regionostergotland.se

15

Andreas Eleftheriou, Department of Neurology, Linköping University Hospital, SE581 85

Linköping, Sweden. Andreas.eleftheriou@ regionostergotland.se 


\section{Abstract}

\section{Background}

The cerebrospinal fluid tap test (CSF TT) is used for selecting shunt surgery candidates in idiopathic normal pressure hydrocephalus (iNPH). Variations in performance, and different outcome measures and cut-off levels in previous research on the CSF TT make comparison of accuracy difficult between studies. We aimed to evaluate the CSF TT, by using the Hellström iNPH scale for shunted iNPH patients with a standardized method.

\section{Methods}

One hundred thirty-two shunt operated iNPH patients were retrospectively included in this study. The gait and balance domains in the iNPH scale were used as outcome measures for the CSF TT and the total iNPH scale score as postoperatively outcome. To identify responders a cut-off level $\geq 5$ points was used. Differences between responders and nonresponders to the CSF TT, as well as the sensitivity, specificity, positive and negative predictive values, accuracy and correlations between outcomes of the CSF TT and postoperatively were calculated.

\section{Results}

In the gait domain, there were $62.9 \%$ responders and correspondingly $42.7 \%$ in the balance domain of the CSF TT. CSF TT responders had significantly better outcomes in both the gait and balance domains but not in the neuropsychology or continence domains postoperatively. The sensitivity and specificity of the CSF TT and the outcome of the total iNPH scale score postoperatively were $67.6 \%$ and $53.3 \%$ for gait and $47.5 \%$ and $73.3 \%$ for balance. For age $\geq$ 80 years, the sensitivity and specificity for gait were $52.2 \%$ and $60.0 \%$, and for age $\leq 80$ years 
$72.2 \%$ and $50.0 \%$. Gait as an outcome measure for both the CSF TT and postoperatively had the highest sensitivity, (73.2\%) and specificity (65.7\%) for all ages.

\section{Conclusions}

The CSF TT, with Hellström’s iNPH scale as the outcome measure, has clear limitations in predicting postoperative results. The gait domain may be used to detect changes of outcomes in gait, but the balance domain is too insensitive to use as an assessment for the CSF TT. The value of the CFS TT for patients over 80 years of age appears to be even lower. Differential diagnostic considerations together with radiological assessments remain cornerstones in selecting eligible shunt responders.

\section{Keywords}

Idiopathic normal pressure hydrocephalus, CSF TT, outcome, accuracy

\section{Introduction}

Idiopathic normal pressure hydrocephalus (iNPH) is a condition that usually has slowly progressive symptoms. In combination with a dilated cerebral ventricular system, the main symptoms are gait disturbance and poor balance, together with cognitive decline and urinary incontinence. The disease is caused by altered cerebrospinal fluid (CSF) dynamics, but the underlying pathophysiology is not fully understood (1). In a recent population-based study, the prevalence of iNPH among individuals 65 years and older, was 3.7\%, and it increased with advancing age (2). The mean age at diagnosis is approximately 70 years (3). A shunt insertion, where CSF is drained from the ventricles, is effective and the result can be 
compared with the effect of levodopa medication in Parkinson's disease (4). Approximately three-quarter of the patients improve after surgery, and the most pronounced effect is on gait performance $(5,6)$.

There should be a focus on optimizing the postoperative shunt outcome. In order to achieve this, a correct diagnosis is fundamental. However, diagnosing iNPH is challenging since the symptoms mimic other neurodegenerative conditions and can also occur in combination with other diseases (7). Therefore, there must be a clear distinction between a diagnosis of iNPH and a positive response to a shunt operation. In recent years, new radiological methods have been introduced for more accurate iNPH diagnosis, such as the disproportionately enlarged subarachnoid space hydrocephalus (DESH) $(8,9)$ and the Radscale (10), but the prediction of shunt outcome in relation to these radiological parameters has not been clarified . CSFdynamic tests with various techniques can be used to evaluate patients with possible iNPH (11). With the lumbar infusion test, the CSF outflow resistance and conductance are measured (12). An elevated resistance has been suggested as a predictor of a positive outcome of shunt surgery (13), but this test has been reported to have low sensitivity $(12,14,15)$. External lumbar drainage of CSF (ELD) for one to several days has a high positive predictive value but requires hospital admission and has an inherent risk for complications (16-18). Less invasive and commonly used is the cerebrospinal tap test (CSF TT), which involves a lumbar puncture (LP) with removal of 30-50 ml CSF and clinical evaluation before and after the LP (19-22). The CSF TT has mostly been associated with a high positive predictive value (PPV) and a low negative predictive value (NPV), meaning that potential shunt responders would be missed if the indication for surgery is based on a negative CSF TT $(22,23)$. The current international guidelines state that the CSF TT can be a tool with prognostic value $(1,24,25)$. However, the relevance of the CSF TT has though been questioned due to the low sensitivity 
$(22,23,26)$. There is no clear definition of what constitutes a positive CSF TT but an objective improvement in gait has been proposed as the most reliable outcome $(27,28)$. The role attributed to the CSF TT in iNPH varies among clinicians, from being considered very valuable to being a test of limited significance. Standardized evaluation methods of the CSF TT would increase the validity and make comparison between different studies easier (29). In our center, we use the Hellström iNPH scale (30) to evaluate outcome in the four domains gait, balance, neuropsychology and continence, after surgery. The gait and balance domains are evaluated before and after the CFS TT. The Hellström iNPH scale is a standardized method that has rarely been used as an outcome measure in the evaluation of the CSF TT $(23,31)$.

\section{Methods}

\section{Aim and design}

The aim of this study was to evaluate the CSF TT, using the Hellström iNPH scale (30) among shunted iNPH patients, in a large single center cohort. This is a retrospective study from Linköping University Hospital, Sweden. The participants were consecutively included between January 2016 and December 2019 and data was recorded from the patient's charts. The study was approved by the Swedish Ethical Review Authority, 2019-02260.

\section{Participants}

Patients with a possible iNPH diagnosis based on the American European guidelines of 2005 (1) and treated with shunt insertion of an adjustable valve, were included. Neuroimaging features for diagnosis were; enlarged ventricles on CT or MR with Evans index > 30, no signs of obstruction to CSF flow and at least one of four supporting features (1). Patients were excluded if there was a lack of data from a CSF TT or the postoperative assessment. Of 173 
120 iNPH patients, 132 were included in the statistical analysis. Of the 41 excluded patients, 22

121 did not undergo the CSF TT, five had been investigated with ELD and 15 patients had no

122 result from the follow-up assessment postoperatively. Of the 15 patients with no follow-up

123 data, eight had shunt complications, five had missing data due to unwillingness to participate

124 and two died. One of the deaths was caused by an acute subdural hematoma two months after

125 shunt surgery and the other by an intracerebral hematoma five days after surgery. A

126 flowchart of inclusion and exclusion is presented in figure 1 and the characteristics of the

127 included and non-included participants are shown in table 1. 
Referrals with clinical and/or radiological suspicion of iNPH

Jan 2016 to Dec 2019 $n=359$

Dismissed due to other diagnosis, unwillingness to participate or not suitable because of serious comorbidity ( $n=173$ )

priate for surgery but other diagnosis than iNPH $(n=13)$ :

10 secondary NPH

2 obstructive NPH

1 congenital hydrocephalus

\section{Patients with iNPH-diagnosis} and shunt surgery $\mathrm{n}=173$

No results from CSF $\Pi$ ( $n=26)$ :

21 no CSF TT

5 ELD only

Missing follow-up ( $n=15)$ :

8 shunt complications

5 unwillingness to participate

2 deceased

Sufficient pre- and postoperative evaluations $n=132$

Figure 1 Flow chart of inclusion and exclusion for 132 iNPH patients with results from CSF TT and follow-up evaluation 
132 A specialized team including neurologists, neurosurgeons, neuro-radiologists,

133 physiotherapists and occupational therapists assessed the patients preoperatively. The occupational therapist and physiotherapist assessments, accomplished within one week before the CSF TT, included all the measurements for gait, balance, neuropsychology and continence in the Hellström iNPH scale (30). All investigations were performed either in the outpatient or inpatient clinic. A neurologist performed the LP, with the patient in a recumbent position. To measure the intracranial pressure (ICP), a spinal fluid manometer was used and the pressure was measured for 30 seconds before removal of CSF. The exact amount of removed CSF was noted. Approximately three hours after the LP, a physiotherapist reassessed the patients, using the measurements within the gait and balance domains in the iNPH scale (30). In addition to

142 the standardized assessments, the gait pattern was video-recorded. Neuropsychology and continence domains were not evaluated in the CSF TT. The patients were offered shunt surgery based on a consensus decision, considering all available clinical, radiological and laboratory data. CSF TT was used as an adjunctive test but a negative CSF TT did not exclude any patient. The scheduled time for follow-up was three months. At this time, the physiotherapist and occupational therapist used the same instruments as preoperatively, including all domains in the iNPH scale (30). We carefully checked that all necessary shunt valve adjustments or shunt revisions had been accomplished before the follow-up.

152 The Hellström iNPH scale (30) is constructed to cover the symptoms of gait, balance, 153 continence and neuropsychology using ordinal ratings and continuous measures. The gait domain score is calculated from a combination of an eight-grade ordinal gait scale, grading 
the gait severity (figure 2) and the number of steps and time in seconds needed to walk 10 meters. Balance is measured with a seven-grade ordinal scale (figure 2) and continence with a six-grade ordinal scale. The neuropsychology domain uses four continuous measures. A limit of $\geq 5$ points for the total iNPH scale is proposed as an improvement after surgery (30).

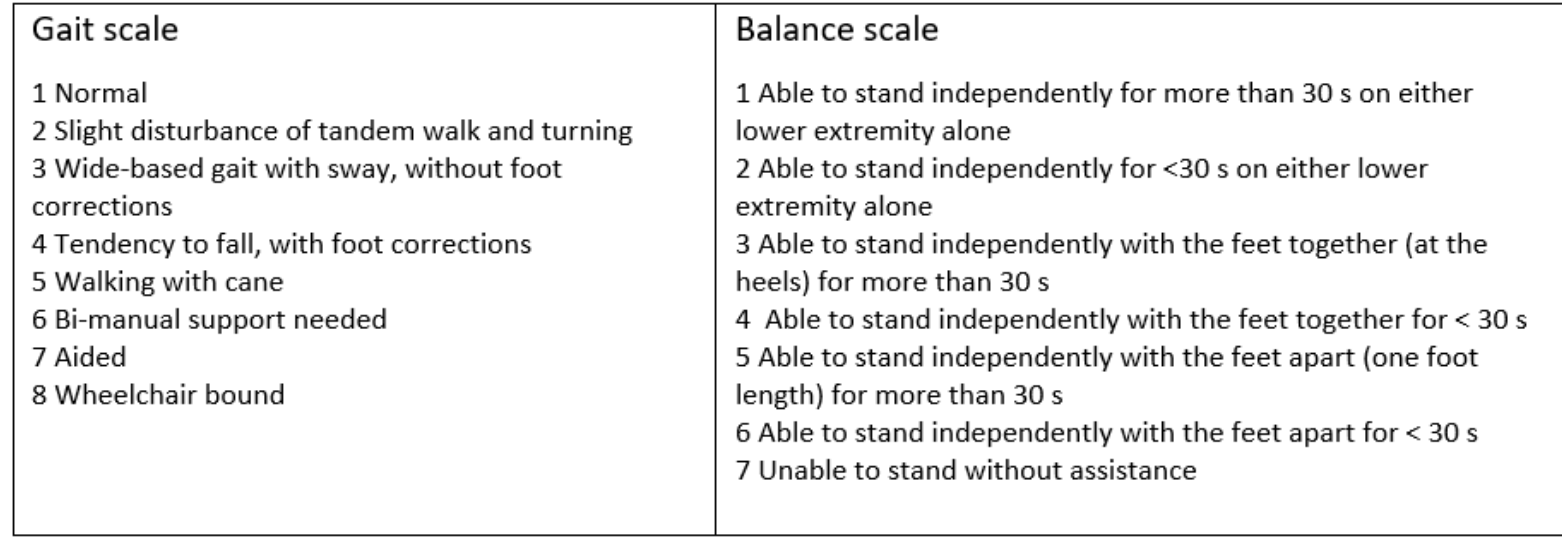

Figure 2 The ordinal grading steps for gait and balance in the Hellström iNPH scale (30).

The results in each domain are converted to a 0-100 score, where 100 represents the performance of an age-matched healthy population. In the total score, the gait domain is double weighted. If any domain has missing data, the total score is calculated with the available data (30), (figure 3).

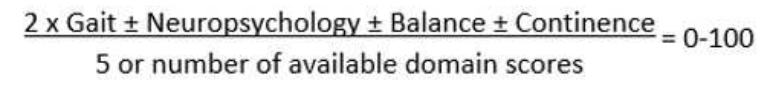

Figure 3 Calculation of the total iNPH scale score (30).

\section{Statistical analysis}

Normal distribution was tested with the Kolmogorov-Smirnov test. Normal distributed variables were presented with mean and Standard Deviations (SD), otherwise with median and interquartile range (IQR) or absolute and relative frequencies. A Mann-Whitney $\mathrm{U}$ test or $\mathrm{Chi}^{2}$ test were used for comparisons between groups of included and non-included patients 
and for comparison between responders and non-responders in the CSF TT. An improvement of $\geq 5$ points for the gait and balance domain on the iNPH scale was considered to indicate a positive responder in the CSF TT. Sensitivity, specificity, positive and negative predictive values and accuracy were calculated. The Spearman rank-order test was used to calculate correlation between variables. The level of significance was set to $\leq 0.05$. Statistical analysis was carried out using IBM SPSS Statistics version 25.0, (IBM Corp. Armonk, NY).

\section{Results}

One hundred and thirty-two individuals, 70 male and 62 female with a mean age of $75.1 \pm 6.2$ years were included in the analysis. Among the 132 individuals, $83(62.9 \%)$ were responders with a positive outcome ( $\geq 5$ points) in the CSF TT in the gait domain on the iNPH scale. For the balance domain, 56 of 131 individuals, (42.7\%), were responders in the CSF TT.

Postoperatively, 102 individuals (77.3\%) improved $\geq 5$ points on the total iNPH scale, with a median improvement of 12 points (IQR: 5.3-18.0). Twenty-four patients (18.2\%) had at least one shunt valve readjustment, 12 patients $(9.1 \%)$ had a shunt revision and the median time to follow-up was 104.5 days (IQR: 45.5-142.8). Demographic variables and information about the opening ICP and drained volume of CSF in the CSF TT are presented in table 1.

Table 1 Characteristics of patients with iNPH diagnosis, included and excluded from data analysis

\begin{tabular}{|c|c|c|c|}
\hline & $\begin{array}{l}\text { Patients included } \\
\qquad(n=132)\end{array}$ & $\begin{array}{l}\text { Patients excluded } \\
(n=41)\end{array}$ & $P$-value \\
\hline Age, years & $75.0(72.0-79.8)$ & $75.0(70.0-78.5)$ & $0.27^{a}$ \\
\hline Sex, male/female (male \%) & $70 / 62(53.0 \%)$ & $28 / 13(68.3 \%)$ & $0.09^{b}$ \\
\hline Hypertension, n (\%) & $79(59.8 \%)$ & $20(48.8 \%)$ & $0.21^{b}$ \\
\hline Diabetes, n (\%) & $37(28.0 \%)$ & $12(29.3 \%)$ & $0.90^{\mathrm{b}}$ \\
\hline Ischemic heart disease, $\mathrm{n}(\%)$ & $29(22.0 \%)$ & $8(19.5 \%)$ & $0.74^{b}$ \\
\hline Stroke, n (\%) & $14(10.6 \%)$ & $4(9.8 \%)$ & $0.88^{b}$ \\
\hline MMSE-SR, n (0-30) & $\begin{array}{c}26.0(22.0-28.0) \\
n=131\end{array}$ & $\begin{array}{c}27.0(23.0-28.0) \\
n=34\end{array}$ & $0.36^{a}$ \\
\hline
\end{tabular}




\begin{tabular}{|c|c|c|c|}
\hline Total iNPH scale score preoperatively, $n$ & $51.0(42.0-63.0)$ & $\begin{array}{c}56.0(40.5-66.0) \\
n=37\end{array}$ & $0.57^{a}$ \\
\hline Volume of CSF drained at CSF TT (ml) & $\begin{array}{c}48.0(44.5-50.0) \\
\quad n=117\end{array}$ & $\begin{array}{c}47.0(41.8-50.0) \\
n=20\end{array}$ & $0.37^{a}$ \\
\hline Opening ICP at CSF TT $\left(\mathrm{cmH}_{2} \mathrm{O}\right)$ & $\begin{array}{c}15.0(12.5-18.0) \\
n=125\end{array}$ & $\begin{array}{c}18.5(14.8-22.1) \\
n=22\end{array}$ & $0.02^{b}$ \\
\hline Positive responder CSF TT Gaitc, n/total (\%) & $84 / 132(63.6 \%)$ & $\begin{array}{c}15 / 23(65.2 \%) \\
n=23\end{array}$ & $0.24^{b}$ \\
\hline Positive responder CSF TT Balance ${ }^{d}$ n/total (\%) & $\begin{array}{c}55 / 131(42.0 \%) \\
n=131\end{array}$ & $\begin{array}{c}7 / 24(29.2 \%) \\
n=24\end{array}$ & $0.24^{b}$ \\
\hline Duration baseline to surgery, days & $125.5(102.0-157.0)$ & $\begin{array}{c}133.5(101.8-171.8) \\
n=34\end{array}$ & $0.26^{\mathrm{a}}$ \\
\hline Duration surgery to follow-up, days & 107.5(90.0-131.0) & $\begin{array}{c}106.0(92.5-158.5) \\
n=25\end{array}$ & $0.61^{a}$ \\
\hline Shunt readjustment before follow-up, $n(\%)$ & $24 / 132(18.2 \%)$ & $11 / 41(26.8 \%)$ & $0.23^{b}$ \\
\hline Shunt revision before follow-up, $\mathrm{n}(\%)$ & $12 / 132(9.1 \%)$ & $13 / 41(30.8 \%)$ & $0.01^{b}$ \\
\hline \multicolumn{4}{|c|}{$\mathrm{a}=$ Independent samples Mann-Whitney $\mathrm{U}$ test, $\mathrm{b}=\mathrm{Chi}^{2}, \mathrm{c}=$ Positive responder CSF TT Gait $=\geq 5$ scores in the gait domain on } \\
\hline
\end{tabular}

The CSF TT responders in the gait domain had significant larger improvements

postoperatively. On the total iNPH scale, responders changed 14.0 (IQR: 7.0-21.0) points

versus non-responders 9.0 (IQR:0-16.0) points compared to evaluation before surgery,

$\mathrm{P}=0.008$. In the gait domain postoperatively, CSF TT responders improved 25.0 (IQR: 11.0-

35.0) points versus non-responders 6.0 (IQR:-4.0-19.5) points, $\mathrm{P}=0.001$. The CSF TT 
Table 2 Pre- and postoperative differences in iNPH scale scores for CSF TT responders and non-responders

\begin{tabular}{|c|c|c|c|c|c|c|}
\hline & $\begin{array}{c}\text { Responder } \\
\text { CSF TT } \\
\text { Gait } \\
(n=83) \\
\text { median, IQR }\end{array}$ & $\begin{array}{c}\text { Non-responder } \\
\text { CSF TT } \\
\text { Gait } \\
(n=49) \\
\text { median, IQR }\end{array}$ & $\begin{array}{c}\mathrm{P}- \\
\text { value }\end{array}$ & $\begin{array}{c}\text { Responder } \\
\text { CSF TT } \\
\text { Balance } \\
(n=56) \\
\text { median, IQR }\end{array}$ & $\begin{array}{c}\text { Non-responder } \\
\text { CSF TT } \\
\text { Balance } \\
(\mathrm{n}=75) \\
\text { median, IQR }\end{array}$ & $\begin{array}{c}\mathrm{P} \text { - } \\
\text { value }\end{array}$ \\
\hline $\begin{array}{l}\triangle \text { iNPH scale } \\
\text { Gait domain, scores }\end{array}$ & $25.0(11.0-35.0)$ & $6.0(-4.0-19.5)$ & $0.01^{\mathrm{a}}$ & $20.0(7.5-35.8)$ & $16.0(3.0-26.0)$ & $0.05^{a}$ \\
\hline $\begin{array}{l}\triangle \text { iNPH scale } \\
\text { Balance domain, scores }\end{array}$ & $0(0-17.0)$ & $0(0-25.0)$ & 0.92 & $16.5(0-34.0)$ & $0(0-0)$ & $0.01^{a}$ \\
\hline $\begin{array}{l}\triangle \text { iNPH scale } \\
\text { Neuropsychology } \\
\text { domain, scores }\end{array}$ & $\begin{array}{c}5.0(-2.8-12.0) \\
n=79\end{array}$ & $\begin{array}{c}3.0(-5.0-10.0) \\
n=43\end{array}$ & 0.31 & $\begin{array}{c}5.0(-2.8-10.0) \\
n=48\end{array}$ & $\begin{array}{c}5.0(-5.0-12.0) \\
n=70\end{array}$ & 0.89 \\
\hline $\begin{array}{l}\triangle \mathrm{iNPH} \text { scale } \\
\text { Continence domain, } \\
\text { scores }\end{array}$ & $\begin{array}{c}0(0-20.0) \\
n=78\end{array}$ & $\begin{array}{c}0(0-30.0) \\
n=45\end{array}$ & 0.32 & $\begin{array}{c}0(0-20.0) \\
n=50\end{array}$ & $\begin{array}{c}0(0-20.0) \\
n=72\end{array}$ & 0.65 \\
\hline $\begin{array}{l}\Delta \text { iNPH scale Total, } \\
\text { scores }\end{array}$ & $14.0(7.0-20.0)$ & $9.0(0-16.0)$ & $0.01^{a}$ & $15.5(7.8-22.8)$ & $9.0(2.0-16.0)$ & $0.01^{a}$ \\
\hline
\end{tabular}

The sensitivity using the gait domain as outcome in the CSF TT and the total iNPH scale as outcome postoperatively was $67.6 \%$ and the PPV $83.1 \%$. The specificity was $53.3 \%$ and the NPV was $32.7 \%$ with an accuracy of $64.4 \%$. For patients $<80$ years, the sensitivity was $72.2 \%$ and for patients $\geq 80$ years it was $52.2 \%$. The PPV was $85.1 \%$ in the younger group and $75.0 \%$ among the elderly. The distributions of specificity in the same age groups were $50.0 \%$ versus $60.0 \%$ and the NPV was $31.3 \%$ versus $35.5 \%$. The accuracy of the CSF TT for patients $<80$ years was $67.7 \%$ and for patients $\geq 80$ years old, $54.5 \%$. of $85.7 \%$. The specificity was $73.3 \%$ and the NPV was $29.3 \%$. The most sensitive output was when using the gait domain as an outcome in the CSF TT and the same outcome

225 postoperatively: sensitivity $73.2 \%$, PPV $85.5 \%$, specificity $65.7 \%$ and NPV $46.9 \%$ for all ages (table 3). 
Table 3 Sensitivity, specificity, PPV, NPP and accuracy of the CSF Tap test with the outcomes Total iNPH Scale and Gait domain postoperatively

\begin{tabular}{|c|c|c|c|}
\hline & $\begin{array}{l}\text { Gait domain CSF TT/ } \\
\text { Total iNPH scale } \\
\text { postoperatively } \\
\text { N=132 }\end{array}$ & $\begin{array}{c}\text { Balance domain CSF TT/ } \\
\text { Total iNPH scale } \\
\text { postoperativelya } \\
\text { N=131 }\end{array}$ & $\begin{array}{l}\text { Gait domain CSF TT/ } \\
\text { Gait domain } \\
\text { postoperativelyb }\end{array}$ \\
\hline Sensitivity & 67.6 & 47.5 & 73.2 \\
\hline Specificity & 53.3 & 73.3 & 65.7 \\
\hline Positive predictive value & 83.1 & 85.7 & 85.5 \\
\hline Negative predictive value & 32.7 & 29.3 & 46.9 \\
\hline Accuracy & 64.4 & 53.4 & 71.2 \\
\hline \multicolumn{4}{|c|}{ Sensitivity, specificity, positive predictive value, negative predictive value and accuracy for CSF TT with cut off $\geq 5$ points in } \\
\hline
\end{tabular}

The change in the gait domain score at the CFS TT correlated significantly with change in outcome postoperatively in the total iNPH score, $\mathrm{r}=0.32, \mathrm{p}=0.01$ as well as with the change in the gait domain score separately, $\mathrm{r}=0.51, \mathrm{p}=0.01$. When using the gait domain score as an outcome in the CSF TT and the total iNPH scale score postoperatively, 69 of 132 (52\%) individuals were true positive, $14(11 \%)$ were false positive, $33(25 \%)$ were false negative and $16(12 \%)$ were true negative. With the outcome gait domain score at the CFS TT and the same outcome postoperatively, 71 of $132(54 \%)$ were true positive, $12(9 \%)$ were false

241 positive, $26(20 \%)$ were false negative and $23(17 \%)$ were true negative (figure 4 and 5).

The correlation between changes in the balance domain in the CSF TT and change in the total

244 iNPH scale score postoperatively was $r=0.59, \mathrm{p}=0.01$. Seventy-one individuals had no change 245 in the balance domain score in the CSF TT. 


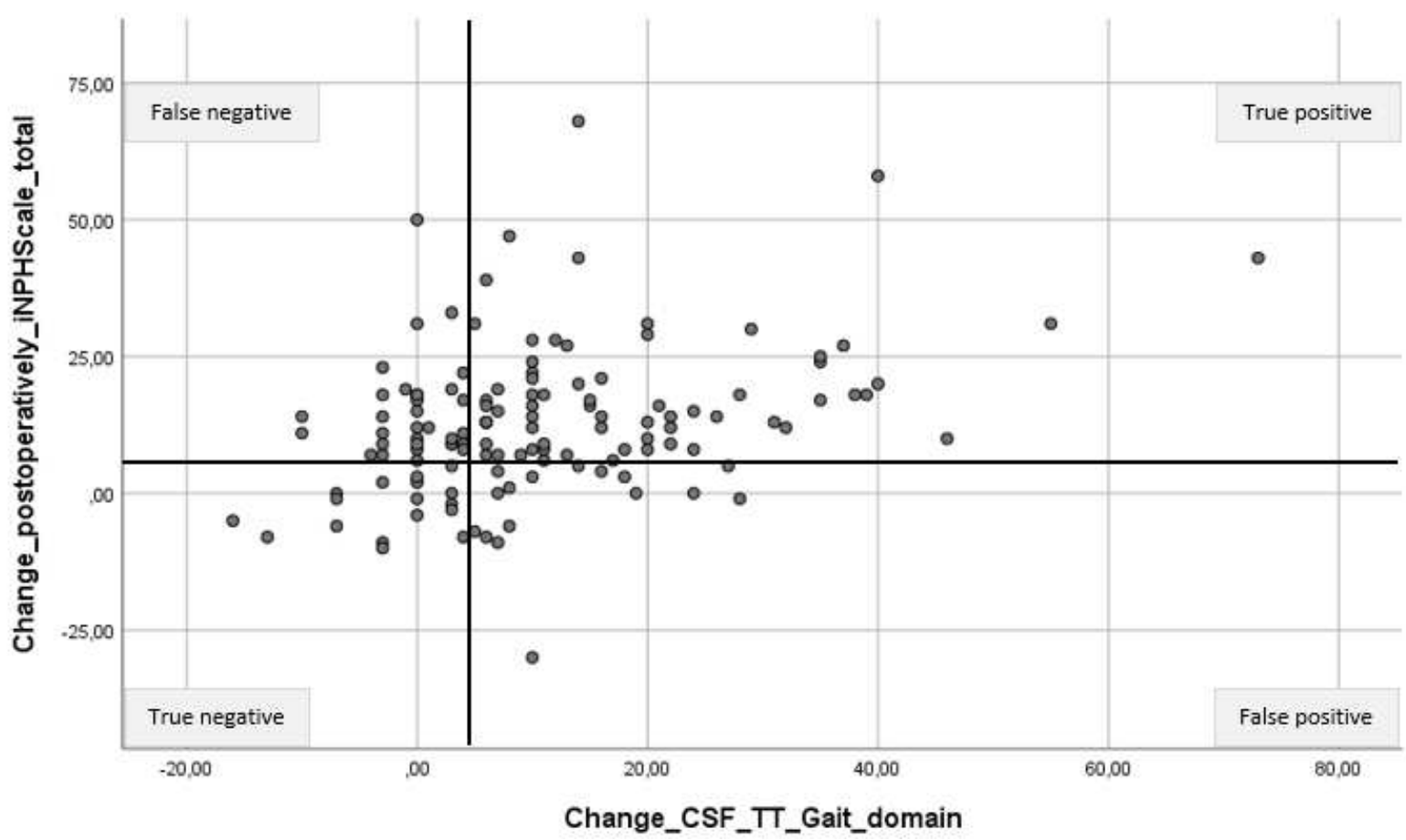

Figure 4 Correlation between changes in the CSF TT in the gait domain on the iNPH scale and changes in the total iNPH scale score postoperatively, Spearman's rho, $r=0.32, p=0.01$. Distribution of true and false, positive and negative outcomes in the

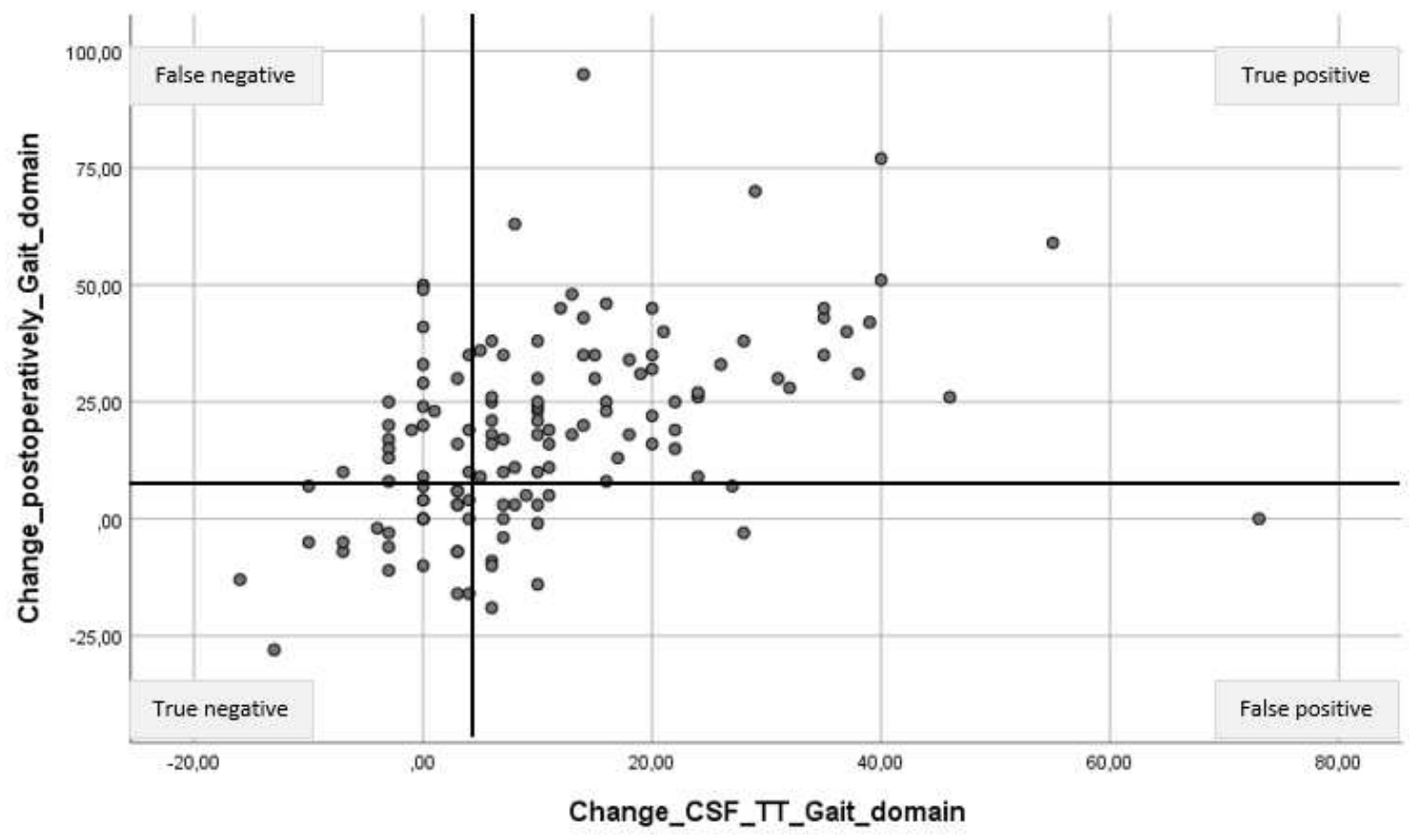

Figure 5 Correlation between changes in the CSF TT in the gait domain on the iNPH scale and changes in the gait domain postoperatively, Spearman's rho, $r=0.51, p=0.01$. Distribution of true and false, positive and negative outcomes in the CSF TT with bold lines at the five-point level of improvement. $\mathrm{N}=132$. 
259 The accuracy of predicting a favorable postoperative result from the CSF TT, using the

260 Hellström iNPH scale as an outcome parameter, shows clear limitations. The cause of this

261 limitation of the CSF TT may partly be a physiological phenomenon that is not possible to

262 overcome.

263 In this single center study a structured CSF TT procedure is used, with control of drained

264 volume, ICP and a careful process for follow-up and treating complications. Despite this, the 265 negative predictive value remains low.

266 We used two different outcomes of the CSF TT, gait and balance. The iNPH scale is

267 constructed to cover the most characteristic features in iNPH and to discriminate between patients with variations in symptoms and between patients and healthy individuals (30). The fact that $54 \%$ (71/131 individuals) had an unchanged balance score in the CSF TT indicates that the balance domain is too insensitive to discriminate small changes. Hellström et. al. (2012) were aware of the limitations in separating patients with different levels of symptom severity with the ordinal rating scale used in the balance domain (30).

The four domains of the iNPH scale are related but none of the domains could be excluded (30). It is evident that a positive response in the CSF TT in the gait and balance domains is not favorable for surgery outcome of neuropsychology, or for continence. This should not be surprising, but is still worth mentioning. In our results, as in previous research $(23,32,33)$, gait is the most valid variable for detecting change in the CSF TT. When we used the gait domain, with a cut of level of $>5$ points in the CSF TT and the same outcome postoperatively, the sensitivity was $73.2 \%$ and the specificity was $65.7 \%$. These results are in line with a Japanese multicenter study (33) using the iNPH grading scale with a four-step ordinal scale grading gait, cognition, continence and a total score (34). Ishikawa and colleagues (2012) used the 
modified Rankin scale as the outcome postoperatively. Eighty percent of the shunted participants were responders, and the sensitivity in the CSF TT, with the total iNPH grading scale score as the outcome, was $71.3 \%$ and the specificity was $65.0 \%$. When using the gait scale score separately to the CSF TT (measured 1-2 days after the LP) the sensitivity decreased to $51.3 \%$ and the specificity increased to $85.0 \%$ (33). The difference in outcome measures and timing for assessment, limits the comparability between the studies. The choice of outcome measure and defining a cut-off value is essential in all evaluations. Precision, practical feasibility, clinical relevance and meaningfulness for the patients have to be considered. Gallagher et al. (2019) used the Global Rating of Change Scale to evaluate the patient's perceived improvement to detect minimal clinically important differences of the CSF TT. For example, the cut-off for the Timed up and Go test was a change of $13 \%$ and for the Timed up and Go test with an added cognitive task, it was a change of $11 \%$ (35). The cutoff $>5$ points in the total iNPH scale, is suggested by the authors to identify outcome postoperatively (30). The same cut-off level for the separate domains of gait and balance in the CSF TT has not been described, and this could be a limitation of our study.

In the European iNPH multicenter study, using the Hellström iNPH scale, a correlation between the CSF TT and outcome post-surgery was only found in the gait domain, with a low correlation $(r=0.22)(23)$. In our study the correlation for the gait domain was higher $(r=0.51)$. In the same study by Wikkelsø and colleagues (2013), the sensitivity (the total iNPH scale score both in the CSF TT and postoperatively), was $52.0 \%$ and the specificity was $59 \%$. The authors mentioned the suboptimal methodology as a cause of the low predictive value (23). Even taking into account that our study is retrospective, the structured procedure and few dropouts probably increased the validity. 
Seventy-seven percent of the operated participants improved on the total iNPH scale score after surgery, which is in line with the $75.0 \%$ improvement rate recently reported (5). The positive outcome rate for the gait domain of the CSF TT was $62.9 \%$ and $42.7 \%$ for the balance domain. The CSF TT was only an adjunctive test and the broad clinical assessments together with analysis of radiological characteristics and information on alternative explanations is probably the reason of the better postoperative outcome.

Even with the high PPV in our study, we had 14 of 132 individuals with a positive response in the CSF TT in the gait domain and a negative outcome at surgery in the total scale score.

Deterioration in the other domains postoperatively could be an explanation, but when using the gait domain as the outcome from both the CSF TT and postoperatively the pattern remains (12 of 132). This is a retrospective study and thus a reflection of clinical routine, i.e. there was no blinding and both the patients and the assessors knew the conditions concerning the assessment routines. Thus, a placebo effect could be, at least partially, an explanation. The placebo effect is not evaluated in the CSF TT. Gupta and Lang (2011) described a case report of a sham procedure in the CSF TT. In their case, walking time decreased about $30 \%$ with both the sham procedure and the large-volume CSF TT (36). Another reason for the false positive results may be shunt dysfunctions at the follow-up. In our study, we had an accurate registration of shunt readjustments and complications. The follow-up results were registered with the shunt valves in the proper condition.

The diagnostic accuracy is strikingly low when evaluating patients over 80 years of age. The sensitivity of $52.2 \%$ for the gait domain means that the prediction of a postoperative positive outcome is slightly better than pure chance. Increased age has been reported as a negative factor for shunt surgery outcome $(31,37)$ but it has also been reported that the age alone 
should not exclude patients from surgery $(38,39)$. A careful evaluation of patients over 80 years of age is important and the low accuracy of CSF TT for these patients has to be taken into consideration when deciding to offer a shunt operation.

Due to the high positive predictive value, there are those who support the use of the CSF TT as an additional test to detect ideal shunt candidates. The low negative predictive value emphasizes not excluding patients from surgery $(24,25,29)$. Even with the standardized methodology in this present study, the diagnostic accuracy of the CSF TT is still limited. An accurate evaluation of other clinical symptoms together with a selective radiological assessment and meticulous consideration about other explanatory diagnosis are important aspects to take into account when selecting patients for shunt surgery.

\section{Strengths and limitations}

A limitation of this study is the retrospective design. We included patients over a period of four years and there were different examiners during that period. The fact that this is a single center study from a selected area in Sweden could even be a limitation. However, strengths of the study are that we used a standardized protocol and prospective inclusion. Using the robust iNPH scale, which tolerates missing values, is a strength and we had few missing data in the included material. The iNPH scale is valid when measuring outcome after surgery and we used a standardized cut-off level. The post CSF TT assessment was measured about three hours after the LP and we used no repetition. Virhammar and colleagues (2012) have reported that improvements in gait can occur with repeated measures, within 24 hours after the LP, if previous measurements were negative (40). Negative outcomes at the time point of three 
356 hours, in the present study, could have been falsely negative. Another limitation is the lack of

357 data from the patients who were not selected for surgery.

\section{Conclusions}

359 Using the gait domain in the Hellström iNPH scale for CSF TT can detect positive outcomes

360 in gait after surgery but the negative predictive value is low. The balance domain is too

361 insensitive to use as an assessment of the CSF TT. Clinical examinations, accurate

362 radiological assessments and careful consideration of other explanations to cover all aspects

363 of iNPH are important to find patients suitable for shunt surgery. The CSF TT is just a tool to

364 predict positive outcome of the gait domain and can be used as a supplement. The CSF TT

365 should be used even more carefully with patients over 80 years of age.

\section{List of abbreviations}

$368 \mathrm{cmH}_{2} \mathrm{O} \quad$ centimeters of water

369 CSF cerebrospinal fluid

370 CSF TT cerebrospinal fluid tap test

371 ELD external lumbar cerebrospinal fluid drainage

372 ICP intracranial pressure

373 iNPH idiopathic normal pressure hydrocephalus

374 IQR Interquartile range

375 LP Lumbar puncture

$376 \mathrm{ml} \quad$ milliliter 
377 MMSE-SR Mini-Mental State Examination, Swedish revision

378

379 Declarations

380

381

382

383

384

385

386

387

388

389

390

391

392

393

394

395

396

397

\section{Ethical approval and consent to participate}

The study was approved by the Swedish Ethical Review Authority, 2019-02260.

\section{Consent for publication}

Not applicable.

\section{Availability of data and materials}

The materials and datasets are available from the corresponding author on reasonable request.

\section{Competing interests}

The authors declare that they have no competing interests.

\section{Funding}

Not applicable.

Authors JR and FL designed the study. JR performed the data collection and analyzed the results. JR, FL and AE interpreted the results, wrote the paper and approved the manuscript. 
Not applicable.

\section{References}

403

404

405

406

407

1. Relkin N, Marmarou A, Klinge P, Bergsneider M, Black PML. INPH guidelines, part II: Diagnosing idio-pathic normal-pressure hydrocephalus [Internet]. Vol. 57, Neurosurgery. Lippincott Williams and Wilkins; 2005 [cited 2020 Nov 2]. Available from: https://doiorg.e.bibl.liu.se/10.1227/01.NEU.0000168185.29659.C5

2. Andersson J, Rosell M, Kockum K, Lilja-Lund O, Söderström L, Laurell K. Prevalence of idiopathic normal pressure hydrocephalus: A prospective, population based study [Internet]. Vol. 14, PLOS ONE. Public Library of Science; 2019 [cited 2020 Nov 2]. Available from: https://doi.org/10.1371/journal.pone.0217705

3. Toma AK, Papadopoulos MC, Stapleton S, Kitchen ND, Watkins LD. Systematic review of the outcome of shunt surgery in idiopathic normal-pressure hydrocephalus. In: Acta Neurochirurgica [Internet]. Acta Neurochir (Wien); 2013 [cited 2020 Nov 2]. p. 1977-80. Available from: https://doi-org.e.bibl.liu.se/10.1007/s00701-013-1835-5

4. Dibilio V, Nicoletti A, Mostile G, Toscano S, Luca A, Raciti L, et al. Dopaminergic and nondopaminergic gait components assessed by instrumented timed up and go test in Parkinson's disease. J Neural Transm [Internet]. 2017 Dec 1 [cited 2020 Nov 2];124(12):1539-46. Available from: https://doi-org.e.bibl.liu.se/10.1007/s00702-017-1794-8

5. Giordan E, Palandri G, Lanzino G, Murad MH, Elder BD. Outcomes and complications of different surgical treatments for idiopathic normal pressure hydrocephalus: A systematic review and meta-analysis [Internet]. Vol. 131, Journal of Neurosurgery. American Association of Neurological Surgeons; 2019 [cited 2020 Nov 5]. p. 1024-36. Available from: https://doi.org/10.3171/2018.5.JNS1875

6. Cage TA, Auguste KI, Wrensch M, Wu YW, Gupta N. Self-reported functional outcome after surgical intervention in patients with idiopathic normal pressure hydrocephalus. J Clin Neurosci [Internet]. 2011 May [cited 2020 Nov 3];18(5):649-54. Available from: https://doi.org/10.1016/j.jocn.2010.08.028

7. Malm J, Graff-Radford NR, Ishikawa M, Kristensen B, Leinonen V, Mori E, et al. Influence of comorbidities in idiopathic normal pressure hydrocephalus - research and clinical care. A report of the ISHCSF task force on comorbidities in INPH. Fluids Barriers CNS [Internet]. 2013 Jun 10 [cited 2020 Nov 2];10(1). Available from: https://doi.org/10.1186/2045-8118-10-22

8. Hashimoto M, Ishikawa M, Mori E, Kuwana N. Diagnosis of idiopathic normal pressure hydrocephalus is supported by MRI-based scheme: A prospective cohort study. Cerebrospinal Fluid Res [Internet]. 2010 Oct 31 [cited 2020 Nov 3];7. Available from: https://doi.org/10.1186/1743-8454-7-18 
9. Ishikawa M, Oowaki H, Matsumoto A, Suzuki T, Furuse M, Nishida N. Clinical significance of cerebrospinal fluid tap test and magnetic resonance imaging/computed tomography findings of tight high convexity in patients with possible idiopathic normal pressure hydrocephalus. Neurol Med Chir (Tokyo) [Internet]. 2010 Feb [cited 2020 Nov 3];50(2):119-23. Available from: https://doi.org/10.2176/nmc.50.119

10. Kockum K, Virhammar J, Riklund K, Söderström L, Larsson EM, Laurell K. Diagnostic accuracy of the iNPH Radscale in idiopathic normal pressure hydrocephalus. PLoS One [Internet]. 2020 Apr 1 [cited 2020 Nov 3];15(4). Available from: https://doi.org/10.1371/journal.pone.0232275

11. Isaacs AM, Williams MA, Hamilton MG. Current Update on Treatment Strategies for Idiopathic Normal Pressure Hydrocephalus [Internet]. Vol. 21, Current Treatment Options in Neurology. Springer; 2019 [cited 2020 Nov 3]. Available from: https://doiorg.e.bibl.liu.se/10.1007/s11940-019-0604-z

12. Eklund A, Smielewski P, Chambers I, Alperin N, Malm J, Czosnyka M, et al. Assessment of cerebrospinal fluid outflow resistance [Internet]. Vol. 45, Medical and Biological Engineering and Computing. Med Biol Eng Comput; 2007 [cited 2020 Nov 5]. p. 719-35. Available from: https://doi-org.e.bibl.liu.se/10.1007/s11517-007-0199-5

13. Kim DJ, Kim H, Kim YT, Yoon BC, Czosnyka Z, Park KW, et al. Thresholds of resistance to CSF outflow in predicting shunt responsiveness. Neurol Res [Internet]. 2015 Apr 1 [cited 2020 Nov 5];37(4):332-40. Available from: https://doiorg.e.bibl.liu.se/10.1179/1743132814Y.0000000454

14. Malm J, Kristensen B, Karlsson T, Fagerlund M, Elfverson J, Ekstedt J. The Predictive Value of Cerebrospinal Fluid Dynamic Tests in Patients With the Idiopathic Adult Hydrocephalus Syndrome. Arch Neurol. 1995;52(8):783-9.

15. Mahr C V., Dengl M, Nestler U, Reiss-Zimmermann M, Eichner G, Preuß M, et al. Idiopathic normal pressure hydrocephalus: Diagnostic and predictive value of clinical testing, lumbar drainage, and CSF dynamics. J Neurosurg [Internet]. 2016 Sep 1 [cited 2020 Nov 3];125(3):591-7. Available from: https://doi.org/10.3171/2015.8.JNS151112

16. Chotai S, Medel R, Herial NA, Medhkour A. External lumbar drain: A pragmatic test for prediction of shunt outcomes in idiopathic normal pressure hydrocephalus. Surg Neurol Int [Internet]. 2014 [cited 2020 Nov 5];5(JAN). Available from: https://surgicalneurologyint.com/surgicalint-articles/external-lumbar-drain-a-pragmatic-testfor-prediction-of-shunt-outcomes-in-idiopathic-normal-pressure-hydrocephalus/

17. Gallina P, Lastrucci G, Caini S, Di Lorenzo N, Porfirio B, Scollato A. Accuracy and safety of 1-day external lumbar drainage of CSF for shunt selection in patients with idiopathic normal pressure hydrocephalus. J Neurosurg [Internet]. 2019 Oct 1 [cited 2020 Nov 5];131(4):1011-7. Available from: https://doi.org/10.3171/2018.6.JNS18400

18. Walchenbach R, Geiger E, Thomeer RTWM, Vanneste JAL. The value of temporary external lumbar CSF drainage in predicting the outcome of shunting on normal pressure hydrocephalus. J Neurol Neurosurg \&amp;amp; Psychiatry [Internet]. 2002 Apr 1;72(4):503 LP - 506. Available from: http://jnnp.bmj.com/content/72/4/503.abstract

19. Wikkelsö C, Andersson H, Blomstrand C, Lindqvist G, Svendsen P. Predictive value of the cerebrospinal fluid tap-test. Acta Neurol Scand [Internet]. 1986 [cited 2020 Nov 3];73(6):56673. Available from: https://doi-org.e.bibl.liu.se/10.1111/j.1600-0404.1986.tb04601.x

20. Sand T, Bovim G, Grimse R, Myhr G, Helde G, Cappelen J. Idiopathic normal pressure hydrocephalus: the CSF tap-test may predict the clinical response to shunting. Acta Neurol 
Scand [Internet]. 1994 [cited 2020 Nov 3];89(5):311-6. Available from: https://doiorg.e.bibl.liu.se/10.1111/j.1600-0404.1994.tb02640.x

21. Ishikawa M. Clinical Guidelines for Idiopathic Normal Pressure Hydrocephalus. Neurol Med Chir (Tokyo) [Internet]. 2004 Apr [cited 2020 Nov 9];44(4):222-3. Available from: https://doi.org/10.2176/nmc.44.222

22. Kahlon B, Sundbärg G, Rehncrona S. Comparison between the lumbar infusion and CSF tap tests to predict outcome after shunt surgery in suspected normal pressure hydrocephalus. J Neurol Neurosurg \&amp;amp; Psychiatry [Internet]. 2002 Dec 1;73(6):721 LP - 726. Available from: http://jnnp.bmj.com/content/73/6/721.abstract

23. Wikkels $\varnothing \mathrm{C}$, Hellström P, Klinge PM, Tans JTJ. The European iNPH Multicentre Study on the predictive values of resistance to CSF outflow and the CSF Tap Test in patients with idiopathic normal pressure hydrocephalus. J Neurol Neurosurg Psychiatry [Internet]. 2013 [cited 2020 Nov 2];84(5):562-8. Available from: http://dx.doi.org.e.bibl.liu.se/10.1136/jnnp-2012-303314

24. Marmarou A, Bergsneider M, Klinge P, Relkin N, Black PML. INPH guidelines, part III: The value of supplemental prognostic tests for the preoperative assessment of idiopathic normalpressure hydrocephalus [Internet]. Vol. 57, Neurosurgery. Neurosurgery; 2005 [cited 2020 Nov 2]. Available from: https://doi-org.e.bibl.liu.se/10.1227/01.NEU.0000168184.01002.60

25. Mori E, Ishikawa M, Kato T, Kazui H, Miyake H, Miyajima M, et al. Guidelines for management of idiopathic normal pressure hydrocephalus: Second edition. Neurol Med Chir (Tokyo) [Internet]. 2012 [cited 2020 Nov 2];52(11):775-8. Available from: https://doi.org/10.2176/nmc.52.775

26. Raneri F, Zella MAS, Di Cristofori A, Zarino B, Pluderi M, Spagnoli D. Supplementary Tests in Idiopathic Normal Pressure Hydrocephalus: A Single-Center Experience with a Combined Lumbar Infusion Test and Tap Test. World Neurosurg [Internet]. 2017 Apr 1 [cited 2020 Nov 3];100:567-74. Available from: https://doi.org/10.1016/j.wneu.2017.01.003

27. Ravdin LD, Katzen HL, Jackson AE, Tsakanikas D, Assuras S, Relkin NR. Features of gait most responsive to tap test in normal pressure hydrocephalus. Clin Neurol Neurosurg [Internet]. 2008 May [cited 2020 Nov 2];110(5):455-61. Available from: https://doi.org/10.1016/j.clineuro.2008.02.003

28. de Souza RKM, da Rocha SFB, Martins RT, Kowacs PA, Ramina R. Gait in normal pressure hydrocephalus: Characteristics and effects of the CSF tap test. Arq Neuropsiquiatr [Internet]. 2018 May 1 [cited 2020 Nov 2];76(5):324-31. Available from: https://doi.org/10.1590/0004$282 \times 20180037$

29. Mihalj M, Dolić K, Kolić K, Ledenko V. CSF tap test - Obsolete or appropriate test for predicting shunt responsiveness? A systemic review [Internet]. Vol. 362, Journal of the Neurological Sciences. Elsevier B.V.; 2016 [cited 2020 Nov 2]. p. 78-84. Available from: https://doi.org/10.1016/j.jns.2016.01.028

30. Hellström $P$, Klinge $P$, Tans J, Wikkels $\varnothing C$. A new scale for assessment of severity and outcome in iNPH. Acta Neurol Scand [Internet]. 2012 Oct [cited 2020 Nov 2];126(4):229-37. Available from: http://doi.wiley.com/10.1111/j.1600-0404.2012.01677.x

31. Bådagård H, Braun M, Nilsson D, Stridh L, Virhammar J. Negative predictors of shunt surgery outcome in normal pressure hydrocephalus. Acta Neurol Scand [Internet]. 2020 Mar 1 [cited 2020 Nov 2];141(3):219-25. Available from: https://doi-org.e.bibl.liu.se/10.1111/ane.13200 
tap-test in normal pressure hydrocephalus. Arq Neuropsiquiatr [Internet]. 1997 [cited 2020 Nov 2];55(2):179-85. Available from: https://doi.org/10.1590/S0004-282X1997000200003

33. Ishikawa M, Hashimoto M, Mori E, Kuwana N, Kazui $H$. The value of the cerebrospinal fluid tap test for predicting shunt effectiveness in idiopathic normal pressure hydrocephalus. Fluids Barriers CNS [Internet]. 2012 Jan 13 [cited 2020 Nov 6];9(1). Available from: https://doi.org/10.1186/2045-8118-9-1

34. Kubo Y, Kazui H, Yoshida T, Kito Y, Kimura N, Tokunaga H, et al. Validation of grading scale for evaluating symptoms of idiopathic normal-pressure hydrocephalus. Dement Geriatr Cogn Disord [Internet]. 2007 Dec [cited 2020 Nov 3];25(1):37-45. Available from: https://doi.org/10.1159/000111149

35. Gallagher R, Marquez J, Osmotherly P. Clinimetric Properties and Minimal Clinically Important Differences for a Battery of Gait, Balance, and Cognitive Examinations for the Tap Test in Idiopathic Normal Pressure Hydrocephalus. Clin Neurosurg [Internet]. 2019 Jun 1 [cited 2020 Nov 2];84(6):E378-84. Available from: https://doi-org.e.bibl.liu.se/10.1093/neuros/nyy286

36. Gupta A, Lang AE. Potential placebo effect in assessing idiopathic normal pressure hydrocephalus: Case report. J Neurosurg [Internet]. 2011 May [cited 2020 Nov 2];114(5):1428-31. Available from: https://doi.org/10.3171/2010.12.JNS10106

37. Marmarou A, Young HF, Aygok GA. Estimated incidence of normal pressure hydrocephalus and shunt outcome in patients residing in assisted-living and extended-care facilities. Neurosurg Focus [Internet]. 2007 [cited 2020 Nov 6];22(4). Available from: https://doi.org/10.3171/foc.2007.22.4.2

38. Halperin JJ, Kurlan R, Schwalb JM, Cusimano MD, Gronseth G, Gloss D. Practice guideline: Idiopathic normal pressure hydrocephalus: Response to shunting and predictors of response. Neurology [Internet]. 2015 Dec 8;85(23):2063 LP - 2071. Available from: http://n.neurology.org/content/85/23/2063.abstract

39. Thompson SD, Shand Smith JD, Khan AA, Luoma AMV, Toma AK, Watkins LD. Shunting of the over 80s in normal pressure hydrocephalus. Acta Neurochir (Wien) [Internet]. 2017 Jun 1 [cited 2020 Nov 3];159(6):987-94. Available from: https://doiorg.e.bibl.liu.se/10.1007/s00701-017-3171-7

40. Virhammar J, Cesarini KG, Laurell K. The CSF tap test in normal pressure hydrocephalus: Evaluation time, reliability and the influence of pain. Eur J Neurol [Internet]. 2012 Feb [cited 2020 Nov 2];19(2):271-6. Available from: https://doi-org.e.bibl.liu.se/10.1111/j.14681331.2011.03486.x 


\section{Figures}

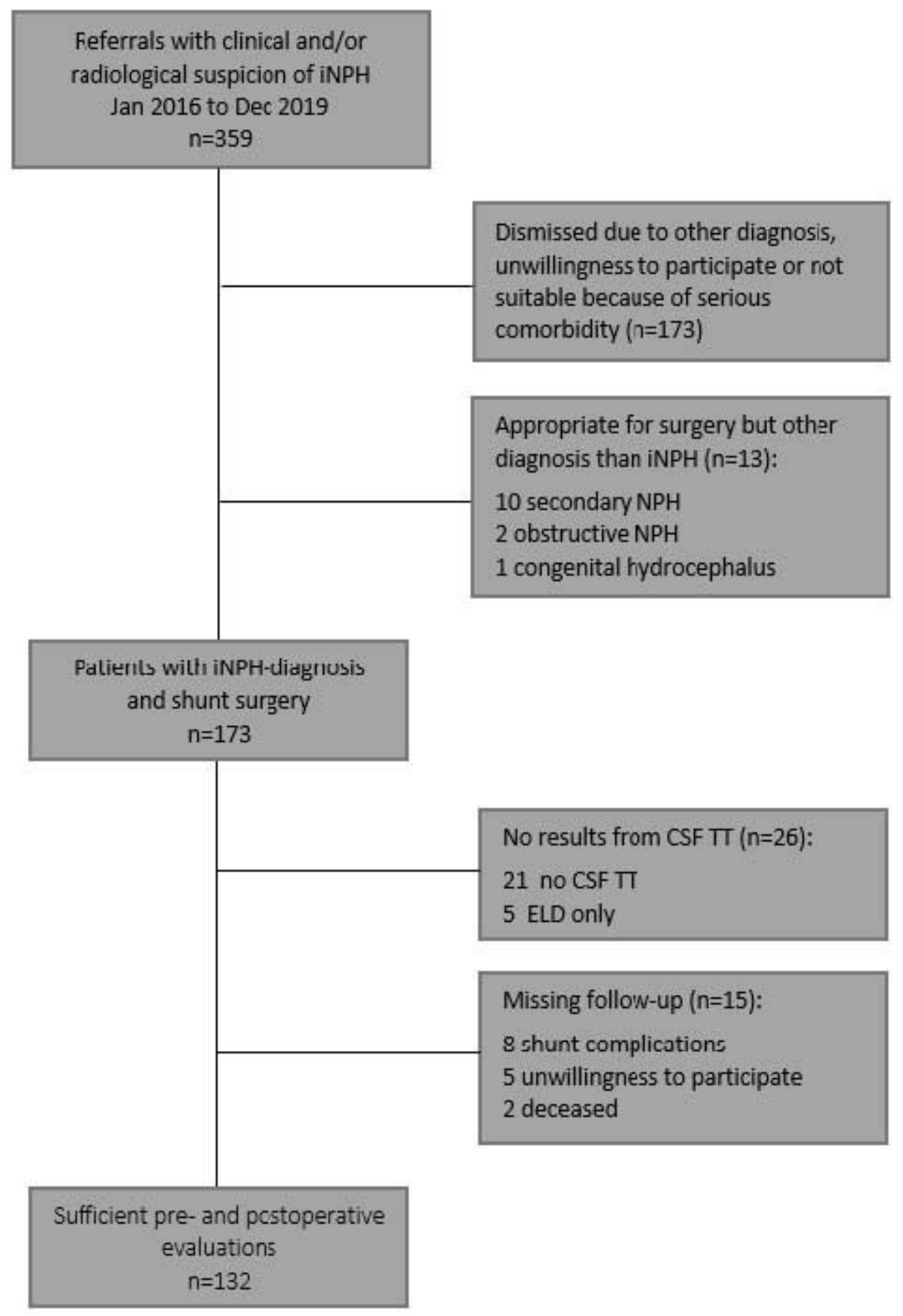

\section{Figure 1}

Flow chart of inclusion and exclusion for $132 \mathrm{iNPH}$ patients with results from CSF TT and follow-up evaluation 


\section{Gait scale}

1 Normal

2 Slight disturbance of tandem walk and turning

3 Wide-based gait with sway, without foot

corrections

4 Tendency to fall, with foot corrections

5 Walking with cane

6 Bi-manual support needed

7 Aided

8 Wheelchair bound

\section{Balance scale}

1 Able to stand independently for more than $30 \mathrm{~s}$ on either lower extremity alone

2 Able to stand independently for $<30 \mathrm{~s}$ on either lower extremity alone

3 Able to stand independently with the feet together (at the heels) for more than $30 \mathrm{~s}$

4 Able to stand independently with the feet together for $<30 \mathrm{~s}$ 5 Able to stand independently with the feet apart (one foot length) for more than $30 \mathrm{~s}$

6 Able to stand independently with the feet apart for $<30 \mathrm{~s}$

7 Unable to stand without assistance

\section{Figure 2}

The ordinal grading steps for gait and balance in the Hellström iNPH scale (30).

\section{$\underline{2 \times \text { Gait } \pm \text { Neuropsychology } \pm \text { Balance } \pm \text { Continence }}=0-100$ 5 or number of available domain scores}

\section{Figure 3}

Calculation of the total iNPH scale score (30).

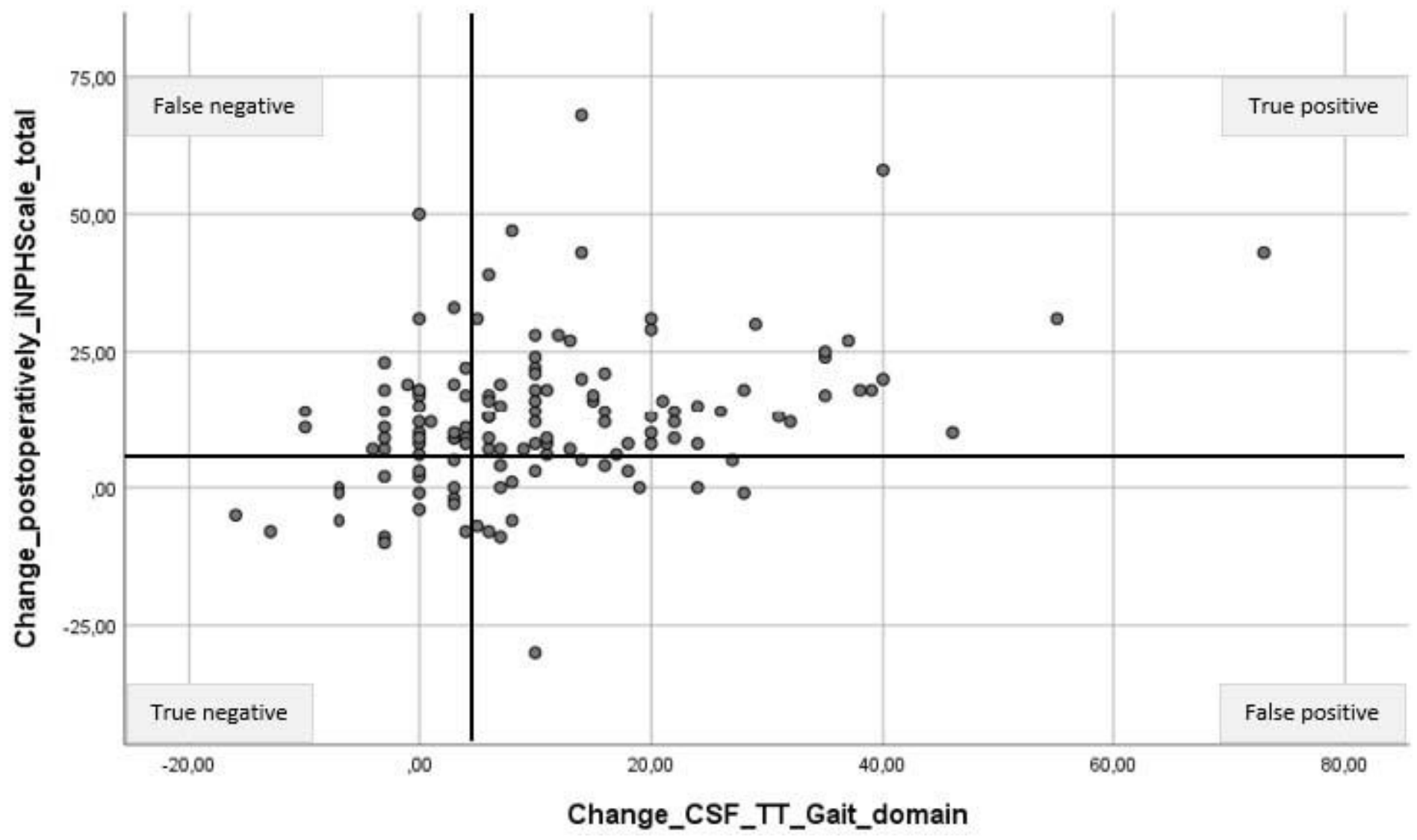


Figure 4

Correlation between changes in the CSF TT in the gait domain on the iNPH scale and changes in the total iNPH scale score postoperatively, Spearman's rho, $r=0.32, p=0.01$. Distribution of true and false, positive and negative outcomes in the CSF TT with bold lines at the five-point level of improvement. N=132.

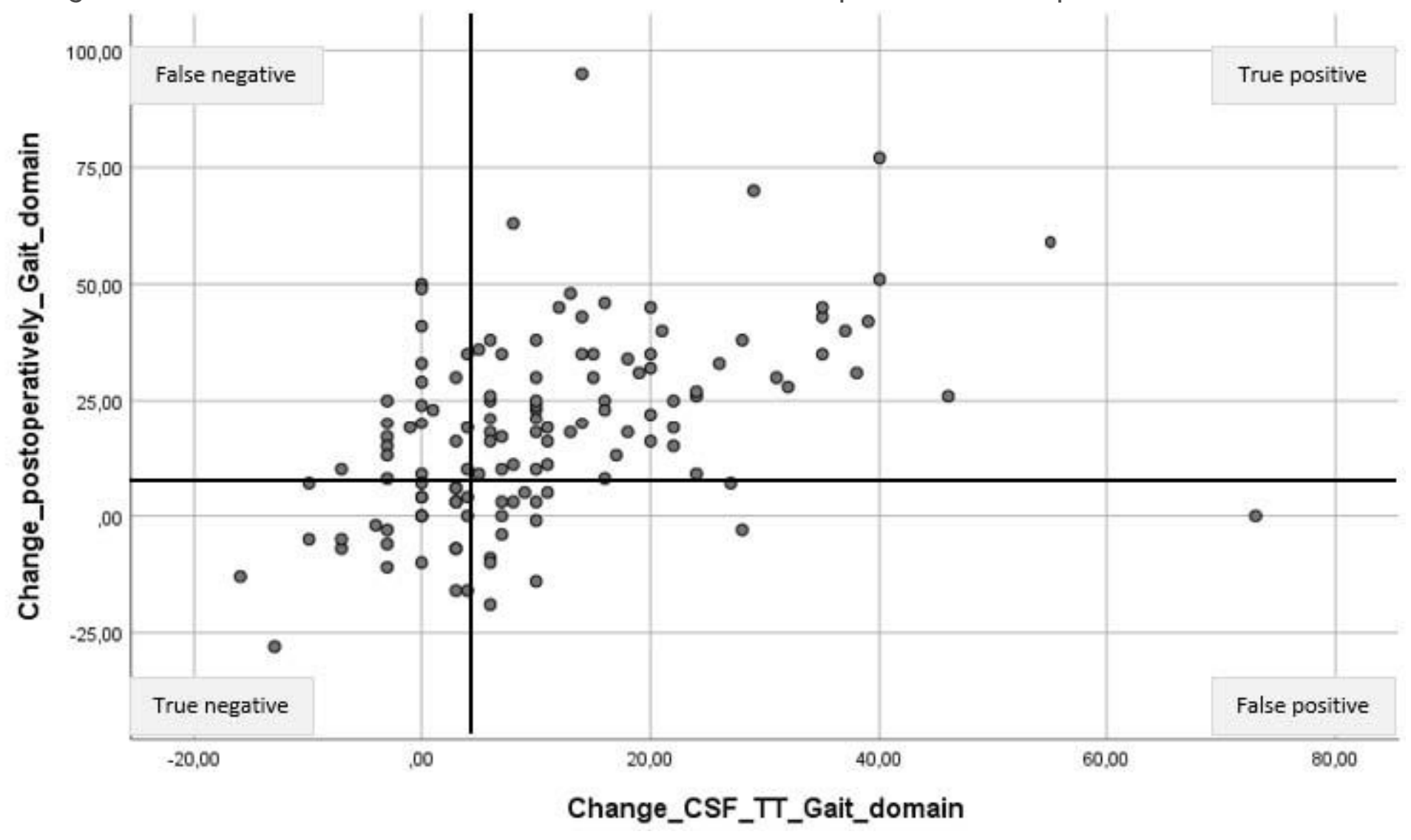

Figure 5

Correlation between changes in the CSF TT in the gait domain on the iNPH scale and changes in the gait domain postoperatively, Spearman's rho, $r=0.51, p=0.01$. Distribution of true and false, positive and negative outcomes in the CSF TT with bold lines at the five-point level of improvement. $N=132$. 